УДК 316.77

DOI 10.18413/2712-7451-2020-39-1-25-35

\title{
ДЕИНДИВИДУАЛИЗАЦИЯ СООБЩЕНИЙ В БЛОГОСФЕРЕ
}

\section{DEINDIVIDUALIZATION OF MESSAGES IN THE BLOGOSPHERE}

\author{
И.В. Привалова \\ I.V. Privalova \\ Саратовский государственный медицинский университет им. В.И. Разумовского, \\ Россия, 410012, г. Саратов, ул. Б. Казачья, 112 \\ Saratov State Medical University, \\ 112 Bolshaya Kazachya St, Saratov, 410012, Russia \\ E-mail: ivprivalova@mail.ru
}

\begin{abstract}
Аннотация
Электронная коммуникация стала ведущим способом передачи информации в XXI веке. Однако специфика данного вида коммуникации ещё не всесторонне изучена. Одной из характерных особенностей электронной коммуникации является потеря персонифицированных характеристик отправляемых сообщений, которую мы предлагаем терминологизировать как «деиндивидуализация», которая понимается автором как модель коммуникативного поведения с особыми принципами презентации сообщений и участия в обмене информацией. Проведенный анализ электронного контента позволил выявить две основные тенденции «массовизации» коммуникативного поведения в блогосфере. Первый тип - деиндивидуализация обобщающего характера, второй тип - исходящая от конкретного адресанта деиндивидуализация, которая существует в двух формах - частичной и полной. Сделан вывод о стирании границ между публичной и личной сферами в цифровом информационном пространстве, и о том, что большинство новостных рейтинговых сообщений де-персонифицированы. Впервые психологический феномен «деиндивидуализации», описанный Г. Лебоном, применяется при рассмотрении особенностей современных коммуникативных процессов. Предлагаемый подход является научным вкладом в теорию массовой коммуникации.
\end{abstract}

\begin{abstract}
Electronic communication has become the leading means of transmitting information in the 21st century. However, the specificity of this type of communication has not yet been comprehensively studied. One of the characteristic features of electronic communication is the loss of personalized characteristics of forwarded messages, what is proposed to be termed as "deindividualization". In this paper, deindividualization is understood as a model of communicative behavior with special principles of presenting messages and participating in the exchange of information. The electronic content has been analyzed with the help of descriptive and introspective methods and two main trends of the "mass character" of communicative behavior in the blogosphere have been discovered. The first type is deindividualization of a general nature and the second type is de-individualization of a particular addressee that exists in partial and complete forms. It has been concluded that the boundaries between public and personal spheres in digital information space are blurred and most news rating messages are depersonalized. The novelty of the presented research is in the fact that for the first time the psychological phenomenon of "deindividualization" (which has been introduced by G. Le Bon) is applied when considering the features of modern communication processes. The proposed approach is thought to be a scientific contribution to the theory of mass communication.
\end{abstract}

Ключевые слова: деиндивидуализация, блогосфера, электронный контент, личная и публичная cфepa.

Keywords: de-individualization, blogosphere, electronic content, personal and public sphere. 


\section{Введение}

Термины «деиндивидуализация» и «блогосфера» имеют широкое применение в разных отраслях научного знания. «Деиндивидуализация» обозначает феномен нивелирования собственного сознания, собственного «Я», и привлекает внимание, в первую очередь, психологов, рассматривающих различные аспекты личностных проявлений. Блогосфера, как совокупность электронных текстов и записей, представляет собой «всеобщее» цифровое общение и анализируется специалистами в области коммуникации. «Деиндивидуализация» и «блогосфера» являются трансдисциплинарными понятиями, исследование которых невозможно ограничить рамками одной отрасли знания, поэтому изучение указанных явлений происходит с использованием различных подходов и с учетом данных всех гуманитарных дисциплин.

Социальная природа феноменов деиндивидуализации и блогосферы очевидна: психолог Гюстав Лебон [2016] предрек наступление эпохи, в которой «массовость» станет особенностью человеческого поведения, а философ Юрген Хабермас [2002] отметил такую тенденцию в эволюции социума, как «массовый» характер человеческого общения. Именно Ю. Хабермас ввел понятие «публичная сфера», которое впоследствии стало базовым при исследовании блогосферы [Habermas, 1991; Хабермас, 2013].

Под деиндивидуализацией личности Г. Лебон понимал специфику поведения человека в большой социальной группе. Он указывал, что в коллективе у индивида могут проявляться несвойственные ему качества: стремление к анонимности, «синхронизация» своих действий с действиями других членов общества [Лебон, 2016, с. 120]. Причастность к социальной группе предполагает соответствие ее интересам, принципам, установкам. Социальные установки начинают превалировать над личными установками индивида, которые происходят «...из образа и стиля жизни, мировозрения, социальной среды, общекультурной подготовки» [Привалова, 1995, с. 6]. В психологии используется термин «мобэффект» (mod - англ. толпа), когда описывается влияние нахождения в социальной группе на поведение индивида. Деиндивидуализация и эмоциональное подчинение группе происходит под воздействием моб-эффекта, проявляющегося как в реальной жизни, так и в процессе виртуального общения. Ранее мы отмечали [Привалова, 2016], что участники электронной коммуникации испытывают моб-эффект, поскольку электронная информация образна, алогична, хаотична и эмоциональна. Импакт образов электронной информации выше, чем импакт образов печатной информации, поэтому участники виртуального общения в соцсетях не всегда адекватно оценивают полученные сообщения, с готовностью откликаются на призывы других пользователей. «Моб-эффект характеризуется спонтанностью и неосознанностью при выполнении действия. Исполнитель теряет индивидуализированные характеристики, критичность, де-персонифицируется и склонен к совершению алогичных, а порой и просто абсурдных поступков» [Привалова, 2016, с. 47].

Современная блогосфера представляет собой совокупность социальных сетей, которую можно квалифицировать как совокупность социальных групп, осуществляющих единый вид деятельности, а именно, виртуальное общение. Все участники социальной сети поддерживают определенный стиль коммуникативного поведения и доверяют внутрисетевой информации больше, чем другим источникам. В данной работе деиндивидуализация понимается как модель коммуникативного поведения, которая предусматривает особые принщипы презентации сообщений и участия в обмене информацией.

\section{Трансдисциплинарный подход \\ в изучении современной коммуникативной реальности: теоретический анализ и постановка проблемы}

Изучение блогосферы базируется на выделении двух дихотомий: «публичная сфера vs частная сфера» (по Ю. Хабермасу) и «индивидуальное vs массовое». Полагаем, что соотношение составляющих этих дихотомий претерпевает изменение в зависимости от условий социальной среды. Согласно Ю. Хабермасу, устные обсуждения политических 
проблем небольшим кругом заинтересованных лиц и обмен «новостными письмами» (news letters) были первым этапом в развитии публичной сферы. На этом этапе индивидуальное и частное превалировало над публичным и массовым. Распространение печатных изданий и развитие публицистики разграничили сферу приватного и публичного выступлений: «...private correspondence contained detailed and current news...only a trickle of this stream of reports passed through the filter of these "news letters" into printed journals» ${ }^{1}[\mathrm{Ha}-$ bermas, 1991, p. 20]. Многолетнее функционирование традиционных масс медиа (пресса, радио, телевидение) узаконило размежевание между публичным и личным, а также индивидуальным и массовым. Но с оформлением самогенерируемого контента (user-generated content) и блогов возникала необходимость пересмотреть соотношение в дихотомиях: «публичная сфера vs частная сфера» и «индивидуальное vs массовое».

В связи с появившимися в XXI веке техническими новшествами исследователи заявляют о рождении «...новой "публичной сферы", формирующейся в интернет-дискурсе» [Казаков, 2013, с. 126]. Полагаем, что нельзя ставить знак равенства между публичной сферой и блогосферой. Так, И.Н. Шамаев справедливо отмечает два момента, из-за которых блогосфера не может быть приравнена к традиционной публичной сфере, а именно: содержание большого объема непубличной информации и попытки государства контролировать электронную информацию [Шамаев, 2014]. Действительно, в социальных сетях находится контент, где представлены сцены жестокости, унижения человеческого достоинства сексуального и корпорального (телесного, физического) характера. Кроме того, содержится много фейковых или несоответствующих действительности метаданных. Государство вырабатывает инструменты контроля за блогосферой, среди которых особое место занимают законодательные акты. Юридические предписания, регламентирующие деятельность интернет-пространства, затрагивают и коммуникативное поведение пользователей соцсетей - предусматриваются реальные сроки наказания за лайки и репосты в Интернете сообщений, содержащих опасную, экстремистскую информацию. Возможности цифрового пространства и его социальная значимость очень велики, что объясняет необходимость государственного контроля, однако принимаемые законы приводят к тому, что «...индексы свободы Интернета, ежемесячно публикуемые некоммерческой организацией "Общество защиты интернета" (ОЗИ), продолжают демонстрировать систематическое падение» [Тигранян, 2018, с. 90].

На наш взгляд, в настоящее время точнее было бы говорить не о новой публичной сфере, а о ее уникальной разновидности - блогосфере или сетевой публичной сфере. Сетевая публичная сфера существует как результат прогресса новейших цифровых технологий и действия глобализационных тенденций, которые проявляются, в том числе, и в стирании «...национальных границ между контентом в Интернете» [Качесова, Мартихина, 2018 , с. 30]. Наряду с этим значительный сегмент сетевой публичной сферы инкорпорирован в традиционные массмедиа, так как современные печатные издания и телевизионные каналы активно используют достижения системы Веб 2.0. Некоторые газеты, журналы и ТВ каналов (например, Russia Today и 5-tv), помимо электронных вариантов, представляют свою информацию на платформах Фейсбук, в видеохостингах и телеграмм-каналах. В связи с этим возникает необходимость пересмотреть соотношение компонентов в дихотомиях: «публичная сфера vs частная сфера» и «индивидуальное vs массовое».

Понятия деиндивидуализации, публичного и личного находятся в тесных онтологических отношениях. Ю. Хабермас предлагает свое видение этих явлений как «индивидуальность» и «личная идентичность». Личная идентичность формируется во взаимодействии человека с другими людьми. Формирование моральных принципов (или «достоинств жизни» в терминологии Ю. Хабермаса) происходит только при соблюдении

1 «Много актуальных новостей подробно обсуждалось в частной переписке, но только незначительная часть этой информации проходила "фильтр приватной корреспонденции" и отражалась в печатных изданиях - газетах и журналах» (перевод здесь и далее автора - И.В. Приваловой). 
«...морально-обязывающего и взаимного нормативно конформного поведения» [Хабермас, 2002, с. 44]. Нельзя не согласиться с высказыванием о том, что «индивидуальное Я возникает на социальном пути» [Хабермас, 2002, с. 45], однако, как показывает современная действительность, при взаимодействии Я с социальным окружением достаточно часто происходит нивелирование Я, утрата личностных характеристик и самостоятельности мышления.

Изучение деиндивидуализации сообщений интересно рассмотреть сквозь призму рассуждений Ю. Хабермаса об эволюции человеческой природы. Размышляя о смысле морализации человеческой природы, Ю. Хабермас утверждает, что общественная модернизация упразднила патриархальность и традиционность, что «...можно понимать как когнитивную адаптацию к объективным условиям жизни» [Хабермас, 2002, с. 36]. Ю. Хабермас приводит пример с появлением новых репродуктивных технологий, при которых была нарушена традиционность процесса рождения живых существ. Тогда, проводя аналогию с этой сентенцией, можно констатировать, что возникновение блогов разрушило «традиционность» процесса передачи информации.

В монографии Ю. Хабермаса «The Structural Transformation of the Public Sphere» [Habermas, 1991] представлен анализ социально-структурных преобразований в публичной сфере (примечательно, что русскоязычный перевод озаглавлен как «Социоструктурная трансформация публичной сферы» [Хабермас, 2013, с. 226]). Указывается на различное содержание термина «публичная сфера» в зависимости от условия осуществления коммуникации. Применяя терминологию современной лингвистики, можно говорить о том, что в различных видах дискурса линия демаркации между личным и публичным проводится по-разному. Ю. Хабермас, сопоставляя сферу политики и сферу литературного мира, приводит пример стирания границ: «The process in which the state-governed public sphere was appropriated by the public of private people making use for their reason and was established as a sphere of criticism of public authority was one of functionally converting the public sphere in the world of letters already equipped with institutions of the public and with forums

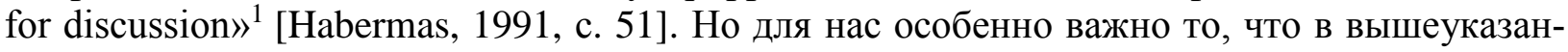
ной работе впервые было отмечено, что блогосфера является примером упразднения рубежей между частным и публичным пространствами: «the tendency toward a mutual infiltration of public and private spheres» ${ }^{2}$ [Habermas, 1991, c. 141]. Таким образом, перемены, которые произошли в социальной среде и в сфере коммуникации, сделали возможным деиндивидуализацию источника информации, появляющейся в массмедиа.

Вне социума человеческая индивидуальность остается неоцененной, и только в сравнении с другими можно понять ее уникальность. Необходима шкала оценки, а социальная среда, как объединение деятельности и взглядов множества индивидуальностей, задает параметры на этой шкале. Осуществляя совместную деятельность с другими членами социума, человек осваивает национально-культурные ценности определенного сообщества, «...которые выполняют определенные функции в механизмах жизни человека: координирующую, стимулирующую, регулирующую и др.» [Привалова, 2002, с. 6].

С другой стороны, инкорпорирование индивидуума в коллектив может привести к потере отличительных свойств и характеристик. Аналогично, нельзя определить оригинальность и достоинство текстов, созданных для личного пользования. Но когда эти тексты предъявляются получателям в информационном пространстве, тогда и становится возможным квалифицировать их оригинальность и индивидуализированные свойства. Возникновение платформ, размещающих пользовательский контент (user-generated

1 «Процесс, при котором государственная публичная сфера стала использоваться группой лиц по своему усмотрению для критики публичной власти, заключался во взаимообратном функциональном преобразовании публичной сферы в сферу частной корреспонденции, которая уже обладала сформированными общественными институтами и форумами для обсуждения».

2 «тенденция к взаимопроникновению публичной и частной сфер» 
content), позволяет оценивать его содержимое и создателям сообщения, и получателям. С появлением новых платформ Веб 2.0 модель передачи сообщений приобрела интерактивный характер. Информация распространяется не только от условного отправителя к условному получателю, но также и в обратном направлении, то есть передача сообщений идет по взаимно-направленным каналам. «Информация распространяется циркулирующими потоками и охватывает невиданное число получателей, которые сами принимают участие в её создании. В случае с коммуникацией на платформах Веб 2.0 и Веб 3.0 отправитель является получателем информации, которую он сам же и создает. Тогда от трёхчленной модели традиционной коммуникации (Отправитель - Сообщение - Получатель), которая применима и к до-компьютерной эпохе, и к коммуникации в Веб 1.0, мы переходим к двухчленной модели, в которой совмещены функции отправителя и получателя информации» [Привалова, 2016, с. 28]. Таким образом, можно говорить об изменениях схем и каналов поступления информации в условиях новой коммуникативной реальности.

В современной интерактивной двухэтапной модели транслирования информации отправляемый контент формируется из нескольких источников. Представим описание наиболее популярных из них. Первый источник - это сообщения в официальных СМИ, на новостных сайтах и в социальных сетях, которые нельзя считать безадресантными. Однако большую часть этих сообщения можно квалифицировать как деиндивидуализированные, поскольку в них представлен ским-контент из различных ресурсов. Вторым источником является индивидуальный пользовательский контент, который, благодаря возможностям платформ Веб 2.0 и Веб 3.0, размещается в электронной среде анонимными пользователями. Этот вид информации «де-юре» де-индивидуализирован вследствие отсутствия задекларированного авторства, и именно анонимный пользовательский контент образует в большинстве своем современную дигитальную блогосферу.

\section{Основные принципы деиндивидуализации сообщений: обсуждение полученных результатов}

Учитывая характер вышеуказанных источников информации, рассмотрим основные случаи, когда «блогосферизация» авторского сообщения может привести к деиндивидуализации и утрате оригинальности. В качестве основных методов для данного исследования применялись интроспективный и описательный методы, а материалом для изучения послужил электронный контент и способы его передачи. Выводы об интерактивном характере современной коммуникативной модели были сделаны на основе данных о специфике современных веб-сайтов и платформ и о способах обмена сообщениями на различных форумах и в социальных сетях.

Отмечены две основные тенденции «массовизации» коммуникативного поведения и деиндивидуализации личных сообщений в блогосфере:

1. Деиндивидуализация обобщающего характера. Сообщения, появляющиеся на официальных электронных порталах (например, yandex.ru, mail.ru), представляют собой новостные резюме, а источник информации обозначается как «СМИ»: «СМИ: США готовят новый пакет санкций против Ирана» (URL: https://eadaily.com/ru/news/); «СМИ: США готовят антимонопольное расследование против IT-гигантов» (URL: https://www.bfm.ru /news/415877); «СМИ: Агент Шюррле предлагал игрока «Краснодару», но клуб отказался» (URL: https://matchtv.ru/football/matchtvnews) и т.д. Помимо того, новостное резюме оформляется по схожей модели с генерализированным указанием на источник под названием «Соцсети»: «Соцсети: жители Оренбурга возмущены эвакуаџией в МОЛЛ «АРМАДА»» (URL: https://56orb.ru/news/incident/04-09-2019/). Интересно, что все чаще новостные телевизионные программы включают в свои трансляции рубрику «По сообщениям пользователей соцсетей» (ГТРК «Вести-Саратов»). В этой рубрике дается обзор наиболее обсуждаемых 
событий, таких как провал асфальтового покрытия, реконструкция кинотеатра, проблемы с вывозом мусора и др. («Обзор соисетей: что сегодня волнует жителей региона», URL: https://gtrk-saratov.ru/obzor-sotssetej-chto-segodnya-volnuet-zhitelej-regiona-22/).

Все большее распространение получают случаи, когда языковая единица «соцсеть», обозначающая используемую для общения платформу, персонифицируется, т.е. происходит олицетворение неодушевленного объекта. При этом наблюдается метонимическое замещение словосочетания «пользователи соцсетей» на «соцсеть». Соцсеть, подобно живому человеку, может испытывать достаточно широкий спектр эмоций - переживать, волноваться, негодовать, восхищаться и т.д. Например: «Страна нищебродов»: соисети возмущень тем, как примориьь поступили с пострадавшим в ДТП» (URL: https://primpress.ru/article/43506); «Соисети негодуют: Reebok призвал российских женшин «пересесть на мужское лицо» (URL: https://fashionunited.ru/novostee/reetyeil/); «Соисети восхищены благородныл поступком китайского водителя» (URL: https://www.5tv.ru/news/154506/). Как видно из примеров, соцсеть берет на себя функции индивидуализированного актора: в сообщениях, основывающихся на данных соцсетей, содержится оценочная характеристика тому или иному событию.

Соцсети используются как площадка для выражения обобщенного, деиндивидуализированного мнения пользователей относительно определенного события: «Соцсети потребовали уволить чиновницу, которая “ничего не должна"» ${ }^{1}$ (URL: https://www.mk.ru/politics/). Деиндивидуализация участников соцсети способствует тому, что публичная сфера выступает «...в качестве среды социальной интеграции, формы социальной солидарности и арены для обсуждения возможных социальных мер действия» [Казаков, 2013, с. 127]. Участники дискуссий могут выразить свою гражданскую позицию по актуальным вопросам, и таким образом многочисленные записи в соцсетях становятся рупором общественного мнения. Власть вступает в реальный и виртуальный диалог по резонансным темам, в результате чего имеют место случаи, когда принимаются административные решения под давлением общественного мнения. Так произошло и с возмутившей пользователей соцсетей чиновницей: «Заявившая о ненужности молодежи чиновница окончательно уволилась» (URL: https://lenta.ru/news/2019/02/11/olga/).

Пожалуй, самая высокая степень неопределенности в указании на адресанта информации наблюдается в тех случаях, когда его обозначают словом «источник»: «Источник: РФС по-прежнему против совмещения Черчесовым постов в сборной и клубе» (URL: https://bobsoccer.ru/user/22098/blog/?item=513154); «Источник: США готовят отключение Pоссии от SWIFT» (URL: https://ruskline.ru/politnews/2. При этом не понятно, что или кто имеется в виду под названием «источник». Это может быть как сообщение из газет, журналов, соцсетей, так и мнение конкретного журналиста или обозревателя, предоставившего информацию на условиях анонимности. Деиндивидуализированная презентация информации в традиционных и электронных СМИ может рассматриваться как один из инструментов конструирования реальности: «С точки зрения социального конструкционизма, масс-медиа производят особый тип реальности - массмедийную реальность, которая является не отражённой в масс-медиа объективной действительностью, а самостоятельной реальностью, относительно автономной по отношению к "объективному миру" и сформированной в соответствии с кодом, разделяемым внутри профессиональной среды» [Дубровская, Кожемякин, 2015, с. 114].

${ }^{1}$ Резонансное событие произошло после высказываний Главы департамента молодежной политики Свердловской области Ольги Глацких о том, что молодежи государство ничего не должно, а должны только родители, которых «не просили никого рожать». 
2. Вторую тенденцию мы характеризуем как исходямую от конкретного адресанта деиндивидуализацию, которая существует в двух формах - частичной и полной.

2.1. Частичная деиндивидуализаџия, исходящая от конкретного адресанта. В дигитальной блогосфере возможно «легализованное» существование одного адресанта под разными именами, что обеспечивает его частичную деиндивидуализацию. Подобно тому как участники бала-маскарада могут предстать в ином обличие, так и участники современных форумов и блогов скрывают свои истинные персоналии под чужими данными (масками). В современной блогосфере существуют инструменты, которые позволяют коммуникантам общаться друг с другом, не раскрывая свои настоящие имена. Посетители сайтов и форумов на платформах Веб 2.0 сами выбирают себе имя (никнейм или ник), свой облик (аватар) и даже биографию (данные профиля). Основным способом создания намеренной анонимности является использование никнеймов и аватаров. Никнейм, как псевдоним для осуществления коммуникации в виртуальном пространстве, позволяет дистанцироваться от собственного имени пользователя и обеспечивает свободу коммуникативного поведения. Такой феномен, как аватар привлекает внимание психологов и психолингвстов и анализируется ими в различных научных ракурсах, например, использование аватаров участниками различных видов электронного дискурса - политического ([Веna Osee, 2019]) или медицинского ([O’Connor, 2019]).

Аватар - это виртуальное «воплощение» пользователя, которое он применяет для взаимодействия с другими участниками дискуссии в электронном пространстве. Примечательно, что и ник и аватар (в той или иной степени) могут соответствовать физиологическому портрету реального человека и отражать его психическое состояние. Предлагается рассматривать аватар как «виртуальное эго» и доказывается, что между аватаром и осознанием себя существует достаточно тесная связь: «An avatar can be called a "virtual ego" and can be defined as “user embodiment in a collaborative virtual environment" "» [Unal et al, 2018, p. 33].

Рассмотрим пример частичной деиндуализации, исходящей от конкретного автора на примере записей пользователей футбольного портала Бобсоккер (https://bobsoccer.ru/). Данный портал был создан и ведется спортивными журналистами с целью освещения новостей мирового футбола, размещения интервью с футболистами, руководителями клубов, тренерами, экспертами, предоставления фото, аудио и видеоматериалов и т.д. Рубрики портала разнобразны и включают онлайн-магазин подарков и трансляции матчей. Интерактивный характер портала обеспечивается такими активностями, как прогнозирование результатов матчей, опросы и форумы. Для того, чтобы иметь возможность принимать участие в обсуждении, необходимо пройти регистрацию на сайте и принять правила общения, несоблюдение которых может привести к наложению заперта или бана (от английского to ban - запрещать). Предполагается обязательное использование никнеймов и аватаров, что позволяет обнародовать свое мнение (иногда достаточно резкое) по различным проблемам: финансовые траты клубов на трансферы, лимит на легионеров, политика формирования национальной сборной и привлечение юных талантов из молодежных клубов. В рубрике «трибуна» можно, не «открывая» имени, разместить мини-заметку и высказаться по интересующей проблеме. Например, посетитель сайта под ником Сэм инициирует дискуссию об участии клуба «Зенит» в турнире «Лига Чемпионов»: «Потерял или приобрел "Зенит" очки в Лионе?». Эксперты портала рассуждают о первом матче «Зенита» в Лиге чемпионов. Эксперт под ником «Эндрю: «До игры мы утверждали, что нас ожидает матч на три исхода. И оказались правы - "Зенит" мог выиграть, мог проиграть, но

1 «Аватар называется "виртуальным эго" и определяется как "воплощение пользователя для взаимодействия с другими пользователями в виртуальной среде"». 
свел встречу в ничью» (https://bobsoccer.ru/sam/blog/?item=511188). Портал «Бобсоккер» использует материалы других электронных ресурсов, таких как «Sky Sports», «Betting Insider», то есть его площадка задействована в формировании международной футбольной блогосферы. Кроме того, материалы из данного портала могут цитироваться футбольными видеоблогерами и участвовать при дальнейшем формировании как индивидуализированного, так и деиндивидуализированного контента.

При исходящей от автора частичной деиндивидуализации следует отметить и такое явление, как «дискурсивная многоликость» адресанта. Участие в тематических форумах можно рассматривать как демонстрацию различных типов коммуникативного поведения одной языковой личности. Действительно, каждый вид дискурса маркирован наличием жанровой специфики, особой стилистики и специализированной лексики. Виды институционального дискурса (юридический, медицинский, экономический) имеют свои правила взаимодействия коммуникантов и терминологию. Например, на электронных медицинских форумах можно встретить примеры профессионального медицинского дискурса и обиходного медицинского дискурса. Порталы электронной юридической консультации предполагают, что адресанты и адресаты сообщений в одинаковой степени владеют основами юридической терминологии. Таким образом, в зависимости от сферы виртуального общения один и тот же пользователь имеет возможность принимать участие в различных коммуникативных ситуациях.

2.2. Полная деиндивидуализачия, исходящая от конкретного адресанта. Вторым типом деиндивидуализированного участия в блогосфере являются случаи, когда исходящее от автора сообщение, отправляется на условиях полной анонимности. Безымянный источник размещает печатный или видео-контент на общедоступной платформе типа Дзен-Яндекс или YouTube. Впоследствии пост неизвестного автора начинает активно обсуждаться в печатных и электронных СМИ и пользователями соцсетей. С появлением смартфонов любой человек может сделать запись какого-то события и разместить эту запись на порталах систем Веб 2.0 и Веб 3.0. Современные технологии позволяют отправителю информации выступать в качестве анонимного источника. Видеосообщение или запись блогера, получившие максимальное количество просмотров и комментариев, становятся топ-новостью. Достаточно часто официальные печатные и электронные СМИ ретранслируют резонансную информацию, сопровождая ее мнениями экспертов. Например, инциденты с зимними авариями на теплотрассах, благодаря видеозаписям, сделанным анонимным владельцем смартфона, попали в блогосферу, а потом уже и в официальную прессу: «Провалился автобус авария теплотрассы сейчас на Димитрова 24. 04.2019 го$\partial a »(\mathrm{URL}:$ https://www.youtube.com/watch?v=isKyP7PvVc0).

Полная деиндивидуализация, исходящая от адресанта, прослеживается и в сообщениях следующего характера: «Кстати, некоторые полагают, что молодые люди сблизились не без стараний со стороны гериогини Йоркской: инсайдеры свидетельствуют, что Ферги прекрасно владеет искусством сводничества» (URL: http://www.marieclaire.ru /psychology /printsessa-beatris). Такие обороты как: «некоторые полагают» и «инсайдеры свидетельствуют» не позволяют серьезно относиться к получаемой информации. В некоторых случаях адресант деиндивидуализирован настолько, что можно поставить под сомнение правдивость представленных сведений: «Европейские футбольные клубы внимательно следят за выступлениями атакующего полузащитника "Спартака" Зелимхана Бакаева, они изучают возможность его подписания, сообщил источник, близкий к футболисту, и собеседник, знакомый с ситуацичей» (URL: https://bobsoccer.ru/user/3180/blog /?item=505842). Характеристика отправителей информации как «источник, близкий к футболисту», и «собеседник, знакомый с ситуацией» вызывают недоверие относительно достоверности данных. Иногда слова «инсайд» или «инсайдер» используются в качестве «полит-корректного» слова «аноним» или словосо- 
четания «анонимный автор»: «"Королева, страна и семья": инсайдер рассказал о главных ценностях в жизни Кейт Миддлтон» (URL: http://www.spletnik.ru/buzz /monarchy/92418). Как видим, деиндивидуализация сообщений связана с проблемой достижимости объективного характера информации [Тертычный, 2018].

\section{Заключение}

Таким образом, современная модель электронной коммуникации может быть охарактеризована как модель интерактивного типа, при которой отмечается взаимнонаправленная циркуляция информационных потоков от адресантов и адресатов информации. В цифровом пространстве отправители и получатели информации взаимодействуют в диалоговом режиме, что стало возможным благодаря возникновению платформ Веб $2.0 \mathrm{c}$ самогенерируемым контентом. В таких условиях формируется новое соотношение личного и публичного, индивидуального и массового. Кроме того, изменяется содержание понятий в дихотомиях: «публичная сфера vs частная сфера» и «индивидуальное vs массовое». Блогосфера является продуктом действия интерактивной модели, а совокупность представленных в ней сообщений образует влиятельный современный ресурс.

Наблюдаются два типа коммуникативного поведения адресантов в блогосфере, которые можно описать с использованием понятия «девиндивидуализация», предложенным Г. Лебоном: деиндивидуализация обобщающего характера и полная или частичная деиндивидуализация конкретного адресанта. В обоих случаях происходит «массовизация» сознания, утрата уникальных характеристик и развивается «де-персонифицированный» характер человеческого общения.

Новизна представленного исследования заключается в том, что впервые психологический термин «деиндивидуализация» применяется при рассмотрении особенностей современных коммуникативных процессов.

\section{Список литературы}

1. Дубровская Т.В., Кожемякин Е.А. 2015. Конструирование межнациональных отношений в СМИ: специфика репрезентаций. Научные ведомости Белгородского государственного университета. Серия: Гуманитарные науки, 18 (215): 111-125.

2. Казаков М.Ю. 2013. «Публичная сфера» Ю. Хабермаса: реализация в интернетдискурсе. Вестник Нижегородского университета им. Н.И. Лобачевского. Серия: Социальные науки, 3 (31): 125-130.

3. Качесова И.Ю., Мартихина Е.В. 2018. Особенности дискурсивных аспектов взаимодействия автора и читателя (на материале анализа контента социальной сети Instagram). Дискурс-Пи, 1 (30): $29-32$.

4. Лебон Г. 2016. Психология народов и масс. Пер. с фр. А. Фридмана, Э. Пименовой. М., Академический проект, 239 p. (Le Bon G. 2009. Lois Psychologiques de l'volution Des Peuples. Kessinger Publishing, 210 p.).

5. Привалова И.В., Купцова Н.В. 2016. Электронная коммуникация молодежи. Саратов, Изд-во Сарат. гос. мед. ун-та, 136 с.

6. Привалова И.В. 2002. Константная вариативность (опыт лингвистического исследования национально-культурных ценностей). В кн.: Язык. Сознание. Коммуникация. Вып. 22. М., ООО «МАКС Пресс»: 5-1.

7. Привалова И.В. 1995. Психологическая установка в процессе понимания иноязычного текста (на материале русского и английского языков). Автореф. дисс. ... канд. филол. наук. Саратов, $18 \mathrm{c}$.

8. Тигранян Е.А. 2018. «Антитеррористический пакет» Яровой: реакция российских и зарубежных изданий. Научные ведомости Белгородского государственного университета. Серия: Гуманитарные науки, 37 (1): 103-112. DOI 10.18413/2075-4574-2018-37-1-103-112 
9. Тертычный А.А. 2018. Объективность информации в СМИ: достижима ли она? Научные ведомости Белгородского государственного университета. Серия: Гуманитарные науки, 37 (1): 113-120. DOI: 10.18413/2075-4574-2018-37-1-113-120

10.Хабермас Ю. 2002. Будущее человеческой природы. Пер. с нем. М., Весь Мир, 144 с.

11.Хабермас Ю. 2013. Социоструктурная трансформация публичной сферы (реферативный перевод Т. Тягуновой). В кн.: Публичная сфера: теория, методология, кейс стади. М., Вариант: 226-266.

12.Шамаев И.Н. 2014. Теория трансформации публичной сферы Юргена Хабермаса и актуальные процессы блогосферы. В кн.: Массовая коммуникация в современном мире: Вызовы и перспективы. Материалы Международной научно-практической конференции студентов, магистрантов и аспирантов (Курск, 16 декабря 2014 г.). Курск, Изд-во Юго-Зап. гос. ун-та: 170-173.

13.Bena Osee U. 2019. Avatars and Sustainability of International Political Systems. Open Journal of Political Science, 09 (02): 243-252.

14. O'Connor S. 2019. Virtual Reality and Avatars in Healthcare. Clinical Nursing Research, 28 (5): 523-528.

15. Unal S., Dalgic T., Akar E. 2018. Avatars as the Virtual World's Personality. The virtual world and marketing (eds. Basar E., Ercis A., Unal S). Cambridge Scholars Publishing: 33-55.

16. Habermas J. 1991. The Structural Transformation of the Public Sphere: An Inquiry into a Category of Bourgeois Society (Translation by Thomas Burger). Cambridge Mass., MIT Press, 301 p.

\section{References}

1. Dubrovskaya T.V., Kozhemyakin E.A. 2015. Konstruirovanie mezhnacional'nyh otnoshenij v SMI: specifika reprezentacij [Media construction of international relations: specifics of representations]. Belgorod State University Scientific Bulletin. Humanities series, 18 (215): 111-125.

2. Kazakov M.Yu. 2013. Publichnaja sfera» Ju. Habermasa: realizacija v internet-diskurse ["Public sphere" of J. Habermas: its realisation in Internet-discourse]. Vestnik of Lobachevsky State University of Nizhni Novgorod by N.I. Lobachevsky. Social Sciences, 3 (31): 125-130.

3. Kachesova I.Yu., Martikhina E.V. 2018. Osobennosti diskursivnykh aspektov vzaimodeystviya avtora i chitatelya (na materiale analiza kontenta sotsial'noy seti Instagram) [Features of the discursive aspects of the interaction between the author and the reader (based on the analysis of the content of the social network Instagram)]. Discourse-P, 1 (30): 29-32.

4. Le Bon G. 2016. Psihologiya narodov i mass [Psychology of Peoples and Masses]. Translated from French by A. Fridman, E. Pimenova. Moscow, Akademicheskij proekt, 239 p. (Le Bon G. 2009. Lois Psychologiques de l'volution Des Peuples. Kessinger Publishing, 210 p.).

5. Privalova I.V., Kuptsova N.V. 2016. Elektronnaya kommunikaciya molodezhi [Digital Communication of the Youth]. Saratov, Izd-vo Sarat. gos. med. un-ta, $136 \mathrm{p}$.

6. Privalova I.V. 2002. Konstantnaya variativnost' (opyt lingvisticheskogo issledovaniya natsional'no-kul'turnykh tsennostey) [Constant variability (linguistic research of national-cultural values)]. In: Yazyk. Soznanie. Kommunikaciya [Language. Consciousness. Communication]. Moscow, OOO "MAKS Press": 5-1.

7. Privalova I.V. 1995. Psihologicheskaya ustanovka v processe ponimaniya inoyazychnogo teksta (na materiale russkogo i anglijskogo yazykov) [Psychological attitude in the understanding of foreign text (based on Russian and English languages)]. Abstract. dis. ... cand. phylolog. sciences. Saratov, 18 p.

8. Tigranyan E.A. 2018. «Yarovaya package» of anti-terrorist amendments: the reaction of Russian and foreign editions. Belgorod State University Scientific Bulletin. Humanities series, 37 (1): 103112 (in Russian). DOI 10.18413/2075-4574-2018-37-1-103-112

9. Tertychny A.A. 2018. Objective information in media: is it reachable? Belgorod State University Scientific Bulletin. Humanities series, 37 (1): 113-120. (in Russian). DOI: 10.18413/2075-45742018-37-1-113-120.

10.Habermas J. 2002. Budushchee chelovecheskoj prirody [The Future of Human Nature]. Translated from German. Moscow, Ves' Mir, 144 p. (Habermas J. 2001. Die Zukunft der menschlichen Natur. Auf dem Weg zu einer liberalen Eugenik? Frankfurt am Main, Suhrkamp Verlag, 125 p.). 
11.Habermas J. 2013. Sotsiostrukturnaya transformatsiya publichnoy sfery [The Structural Transformation of the Public Sphere] (Translated from German by T. Tyagunova). In: Publichnaya sfera: teoriya, metodologiya, kejs stadi [Public sphere: theory, methodology, case study]. Moscow, Variant: 226266.

12.Shamaev I.N. 2014. Teoriya transformatsii publichnoy sfery Yurgena Khabermasa i aktual'nye protsessy blogosfery [The theory of transformation of the public sphere of Jürgen Habermas and the actual processes of the blogosphere]. In: Massovaya kommunikaciya v sovremennom mire: Vyzovy i perspektivy. Materialy Mezhdunarodnoj nauchno-prakticheskoj konferencii studentov, magistrantov i aspirantov [Mass communication in the modern world: Challenges and prospects. Materials of the International scientific-practical conference of students, undergraduates and graduate students] (Kursk, 16 December, 2014). Kursk, Izd-vo Yugo-Zap. gos. un-ta: 170-173.

13.Bena Osee U. 2019. Avatars and Sustainability of International Political Systems. Open Journal of Political Science, 09 (02): 243-252.

14.O'Connor S. 2019. Virtual Reality and Avatars in Healthcare. Clinical Nursing Research, 28 (5): 523-528.

15.Unal S., Dalgic T., Akar E. 2018. Avatars as the Virtual World's Personality. The virtual world and marketing (eds. Basar E., Ercis A., Unal S). Cambridge Scholars Publishing: 33-55.

16. Habermas J. 1991. The Structural Transformation of the Public Sphere: An Inquiry into a Category of Bourgeois Society (Translation by Thomas Burger). Cambridge Mass., MIT Press, 301 p.

\section{Ссылка для цитирования статьи For citation}

Привалова И.В. 2020. Деиндивидуализация сообщений в блогосфере. Вопросы журналистики, педагогики, языкознания, 39 (1): 25-35. DOI 10.18413/2712-7451-2020-39-1-25-35

Privalova I.V. 2020. Deindividualization of messages in the blogosphere. Issues in Journalism, Education, Linguistics, 39 (1): 25-35. (in Russian). DOI10.18413/2712-7451-2020-39-1-25-35 